\title{
Analysis of the Refuse Action Failure of 10kV Circuit Breaker
}

\section{Yang Yingying ${ }^{1}$, Li Yuanyi ${ }^{2}$, Nie Qixin ${ }^{3}$, Qian Cheng ${ }^{3}$, He Lishuai ${ }^{4}$, Shi Diancai ${ }^{1}$, Wang Xue ${ }^{1}$, Zhao Chuanzong ${ }^{1}$, Lin Yuan $^{1}$, Zhang Fusheng ${ }^{1}$}

\author{
${ }^{1}$ State Grid Liaoning Electric Power Co., Ltd. Fushun power supply company. \\ ${ }^{2}$ State Grid Liaoning Electric Power Co., Ltd. Shenyang power supply company. \\ ${ }^{3}$ State Grid Liaoning Research Institute of Electric Power Co., Ltd. \\ ${ }^{4}$ State Grid Liaoning Electric Power Co., Ltd. maintenance branch.
}

Keywords: circuit breaker, refuse action, accident

\begin{abstract}
In power system, the normal operation of power grid is based on the intact equipment. According to the past operation experience, once the abnormal state of circuit breaker rejection occurs in the operation of power network, it is very likely that the accident will happen. And such abnormal state often results in the expansion of power outage, resulting in the recovery of power delay. This paper is combined with several typical cases in the actual operation of the power grid. According to the relevant theoretical norms, some handling principles and experiences are proposed when the circuit breaker refuses to move.
\end{abstract}

\section{Introduction}

$10 \mathrm{kV}$ high voltage circuit breaker, also known as high-voltage switch, can cut off or close the no-load current and load current in high voltage circuit. When the system fails, the circuit breaker has fairly perfect arc extinguishing structure and sufficient interrupting capacity, cutting off overload current and short circuit current. In recent years, gas insulated circuit breakers (C-GIS) have been applied more and more because of their simple structure, small footprint, little environmental impact and low maintenance [2]. However, some manufacturers have not achieved satisfactory results in the design of gas insulated circuit breaker cabinets and mechanical properties and leak detection of circuit breakers. After long-term operation, the potential defects of gas insulated circuit breaker are exposed gradually. In the scheduling work, for example, the daily discontinuation and recovery of the transformer line, the load transfer in the accident handling, and the load cutting in the distribution network, all the above contents will involve the switching operation of the substation circuit breakers. In the case of the Circuit breaker refuse action, it is easy to cause the expansion of the blackout range and the delay of power supply to the blackout users in the case of accident, which leads to the loss of the power supply load.

\section{Analysis of the reasons for the rejection of the circuit breaker}

\subsection{Reason for circuit breaker refusing to switch off}

Circuit breaker cannot normally switch off power, this phenomenon is called rejection opening of the circuit breaker. The reasons for the rejection of the circuit breakers include: the disqualification of the switching voltage or the failure of the relay, the bad contact of the auxiliary contact of the circuit breaker, the broken line or the burning of the trip coil, the broken line or the burning of the trip coil , the low pressure of the hydraulic mechanism to reach the locking value, the two side circuit breakage, and the failure of the operating mechanism. [1]

Because of the backup protection action at the upper level, the bus outage in substation will happen. If it is found that there is a shunt protection action, but the branch circuit breaker does not trip, the rejected circuit breaker should be opened immediately and the power circuit breaker should be restored. If all circuit breakers are not moving, check whether there is any equipment failure in 
the power outage area. If no specific fault points can be found out, all shunting circuit breakers should be opened, and the power circuit breakers should be closed to test them one by one. When the power supply to a branch road, the power circuit breaker once again tripped, it is determined that the sub circuit breaker failure. The circuit breaker is broken again and the rest circuit breakers are returned to normal.

\subsection{Reason of circuit breaker refusing closing}

The circuit breaker cannot normally switch on, this phenomenon is called rejection closing of the circuit breaker.The reasons for the rejection of circuit breakers include: no action of closing iron core, fuse of control loop, bad contact of auxiliary contact of circuit breaker, the abnormal pressure reaches the closing value, the closing control coil is broken, the contact point is not good, the fuse is broken, or the spring mechanism energy storage system is abnormal.

Once the circuit breaker closing is rejected, the closing power supply of the circuit breaker should be disconnected immediately, and then the fault will be dealt with. As the circuit breaker is closed, the closing coil is electrified for a long time, and the closing current is relatively large. The control loop can only connect the closing coil through the closing contactor. Therefore, when there is a breakdown of the closing contactor, it is necessary to disconnect in time to avoid the heating of the coil and the burn of the coil.

\section{Practical case of circuit breaker refuse action}

\subsection{Case analysis of circuit breaker's refusing to switch off in Qingnianlu substation}

Qingnianlu substation bus operation mode is as follows, 1\# main transformer for $10 \mathrm{kV}$ first section bus load, 3\# main transformer for $10 \mathrm{kV}$ fourth section bus load, 2 main transformers run respectively. A "100" bus connection circuit breaker is set between the two buses.

Accident phenomenon: in September 9, 2016, 02:00 monitored the tripping of the "104" 3\# main transformer circuit breaker, and the standby power was not moved, and the $10 \mathrm{kV}$ fourth bus was out of power. The weather was bad and thunderstorm. The OPEN3000 signal is incomplete and does not show specific protective actions. The operator immediately went to the site to check.02:59, the operator arrived at the scene and found that the "145" double bridge overcurrent first segment protection action, the circuit breaker did not act.3\# main transformer overcurrent protection action. The one or two equipment inspection is normal at the site. According to the results of the on-site inspection, the dispatcher makes the analysis, and the fault circuit breaker refuses to move, leading to the main transformer backup protection trip . The specific treatment is as follows.

First, the "145" double bridge circuit breaker was opened. Second, "100" circuit breaker is discontinued. Third, the "104" 3\# main transformer circuit breaker is opened. Fourth, the "145" double bridge circuit breaker is changed from hot standby to cold standby. Fifth, defect treatment. Sixth, 100 bus circuit breaker is enabled. The inspectors reported that there was a breakage of the B and C phases of the "145" double bridge line due to lightning stroke, which should be immediately overhauled. After the "145" double bridge line was changed from cold standby to overhaul, the line inspector carried out the defect treatment. The final inspection conclusion is that the failure of the power supply board of the "145" double bridge protection device causes the circuit breaker to refuse to move.

In this accident, the duty dispatcher takes the 293rd clause of the dispatching regulation of the power system of Fushun power supply company as the basis for processing, that is, "when the main transformer backup protection action is tripped, first should check the protection action of each branch trip, the shunt circuit breaker refuses to jump, that is, the shunt circuit breaker should be opened to restore the main transformer transmission." [3]

\subsection{Case analysis of circuit breaker's refuse refusing to switch off in Wujia substation}

In August 2015, the quick cut protection trip of the circuit breaker in the Wujia substation was successful. The reconnection was successful, and the B phase in the $10 \mathrm{kV}$ third, fourth section was 
grounded. After receiving the report, the dispatcher immediately instructed to pull open the "Qing Wu" tie line breaker. The 2\# main transformer has a circuit breaker protection action tripping. According to this phenomenon, the dispatcher suspected that the circuit breaker refused to switch off. The operator arrives at the scene to check the related equipment. The 2\# main transformer circuit breaker is a backup protection action trip, and the protection device of the "Wuqing" contact line correctly sends out the instructions of the quick cut protection action trip, but the actual circuit breaker does not act. So the conclusion is that the circuit breaker of 2\# main transformer failed to execute the gate order correctly because of the "Qing Wu" tie line circuit breaker, which led to the tripping accident.

\subsection{Case analysis of circuit breaker's refusing closing in Nanyang substation}

In 2016, an accident occurred in a bus tie line breaker, in Nanyang substation. The normal connection mode is adopted at the low pressure side. When the injection power loss occurred, the Nanyang substation bus line breaker issued the correct action instructions, but the circuit breaker did not change into the running state. Eventually, the bus of $10 \mathrm{kV}$ third section of Nanyang substation is out of power. The load on the third $10 \mathrm{kV}$ bus bar is large, and it is in the rush hour. The load transfer time is longer than that of the conventional distribution network. The operator reports the on-site equipment check is normal, and checks the load of the main transformer. The dispatcher instructed the $10 \mathrm{kV}$ third bus to be re-energized through another "100" bus breaker and "102"'103"main transformer circuit breaker.

The specific steps are as follows: first, the fault circuit breaker is discontinued. Second, change the fault circuit breaker from hot standby to cold standby. Third, open the "103" main transformer circuit breaker and close the $220 \mathrm{kV}$ neutral point knife of the $2 \#$ main transformer. Fourth, after the dispatch agreement, the "102" main transformer circuit breaker is opened and the \#2 main transformer differential protection is discontinued to prevent the possible differential current starting differential protection of the two low-voltage side main transformer breakers. Fifth, the "102" main transformer circuit is closed, and the "103" main transformer circuit is closed, and the $10 \mathrm{kV}$ third section bus is re-energized successfully.

\section{Conclusions}

When a circuit breaker fails, the dispatcher must strictly follow the accident treatment process and schedule the operation, and listen to the inspection and analysis report of the operator. At the same time, we should pay attention to the circuit breaker indication signal on the OPEN3000 system, analyze the specific protective action situation in detail, and make an accurate judgement. In dealing with such accidents, relevant personnel should strengthen communication and liaison, strengthen guardianship at the scene, and clarify the division of responsibilities. The relevant personnel should do well in transferring load, isolate faults as soon as possible, and make preparations before resuming transmission. At the same time, a blackout notification is issued to the user in time. Due to the complexity, long time and high difficulty of the circuit breaker failure processing, it is necessary to arrange the personnel to arrive at the accident place quickly so as to minimize the blackout time.

\section{References}

[1] Huang Rui, Zhang Bo, Zhang Jicheng. Discussion on the refuse action factors of $10 \mathrm{kV}$ circuit breaker in substation [J]. Sichuan electric power technology, 2007 (6): 18-19.

[2] Mi zuowei. An analysis of a circuit breaker's refusal to operate [J]. electrical and electrician, 2009 (10): 63-64.

[3] Meng Zhaoming, Zhao Shengping. Field monitoring and fault diagnosis of high voltage cabinet [J]. mechanical engineering

[4] Tang Junhong, Wang Liu, Yang Hongmei, etc. Analysis and treatment of several problems in operation of.10 kV circuit breaker cabinet [J]. Henan electric power, 2009, (4): 34-36. 
[5] He Xiaojun, Xu Zhibin. Research on insulation performance test and fault diagnosis technology of high voltage circuit breaker cabinet [J]. Zhejiang electric power, 2010, (5): 6-10.

[6] Sun Zhiqiang, Wu Yi, Rong man Zhi, et al. Simulation and experimental analysis of the miniature circuit breaker arc chamber. [J]. low voltage electrical appliances, 2010, (3): 1-22. 